\title{
Impact of probiotics, prebiotics and synbiotics on lipid metabolism in humans
}

\author{
Kim G. Jackson and Julie A. Lovegrove* \\ Hugh Sinclair Unit of Human Nutrition and the Institute for Cardiovascular and Metabolic Research (ICMR), \\ Department of Food and Nutritional Sciences, University of Reading, Reading, UK
}

Received 26 November 2012

Accepted 30 January 2013

\begin{abstract}
Public health strategies for reducing the risk of coronary heart disease have focused on lowering plasma lipids, particularly cholesterol levels, with recent studies also highlighting triacylglycerol (TAG) as an important modifiable risk factor. One approach is to supplement the diet with probiotics, prebiotics or synbiotics. Probiotics are live microorganisms which when administered in adequate amounts confer a health benefit on the host. Putative health benefits include improved resistance to gastrointestinal infections, reduction in lipid levels and stimulation of the immune system. Prebiotics are selectively fermented dietary components that are aimed at improving host health through selective fermentation by the gut microbiota, such as bifidobacteria and lactobacilli. Animal studies have shown prebiotics to markedly reduce circulating TAG and to a lesser extent cholesterol concentrations, with favourable but inconsistent findings with respect to changes in lipid levels in human studies. Here we provide an overview of the effects, and possible mechanisms, of probiotics, prebiotics and synbiotics (combination of a probiotic and prebiotic) on circulating lipeamia in humans.
\end{abstract}

Keywords: Probiotics, prebiotics, synbiotics, coronary heart disease, lipids, lactic acid bacteria, short chain fatty acids, inulin

\section{Introduction}

Diseases of the circulatory system account for an appreciable proportion of total morbidity and mortality in adults. Epidemiological studies examining coronary heart disease (CHD) risks in different populations have demonstrated a strong and consistent relationship between total plasma cholesterol and CHD risk $[1,2]$. The positive association is largely confined to the low density lipoprotein (LDL) fraction, which transports approximately $70 \%$ of cholesterol in the bloodstream. High density lipoprotein cholesterol (HDL-C) has been shown to have a strong inverse relationship with CHD development [3]. Low levels of HDL-C are thought to reflect a compromised pathway for the excretion of cholesterol from the body (reverse

*Corresponding author: Professor Julie Lovegrove, Department of Food and Nutritional Sciences, PO Box 226, Whiteknights, University of Reading, Reading RG6 6AP, UK. Tel.: +44 118378 6418; Fax: +44 118378 7708; E-mail: j.a.lovegrove@reading.ac.uk. cholesterol transport) and have been associated with a five-fold increase in CHD risk compared with normal values [4].

In addition to these classical risk factors, elevated levels of triacylglycerol (TAG; major fat in the blood) in both the fasted and fed (postprandial) state has been demonstrated to be associated with CHD in a number of observational studies [5]. Only more recently have three prospective cohort studies confirmed raised postprandial TAG to be an independent risk factor for CHD [6-8], and more discriminatory than fasting TAG in some population groups such as women [6, 8]. Delayed clearance of TAG from the circulation has been proposed to drive the remodelling of the lipid contents of HDL and LDL by neutral lipid exchange leading to a reduction in HDL-C concentration and an increased prevalence of small dense LDL cholesterol (LDL-C) [9]. This lipid profile has been reported in men with established CHD and those classified with the atherogenic lipoprotein phenotype and the metabolic syndrome $[10,11]$. 
Increasing prevalence of dyslipidaemia in the population, associated with the rising rates of obesity and type II diabetes, has generated considerable interest in dietary strategies which can reduce circulating lipid levels in both the fed and fasted state and which also offer long-term efficacy comparable with most effective drug treatments. Although low-fat, high carbohydrate diets have been proposed for the primary management of CHD, long-term compliance to such diets is difficult to maintain and there is evidence for potentially detrimental metabolic effects in some population groups, such as type II diabetics [12]. One dietary strategy which has been proposed to benefit the lipid profile, involves the supplementation of the diet with probiotics, prebiotics and synbiotics (a combination of probiotics and prebiotics) which are mechanisms to improve the health of the host by supplementation and/or fortification of certain health promoting gut bacteria. There have been a number of reviews on the impact of probiotics and prebiotics on CVD risk factors including immune function [13] and obesity [14]. This review will solely focus on the effects of probiotics, prebiotics and synbiotics on lipid metabolism in humans, and discuss potential mechanisms of action.

\section{Probiotics (including fermented milk products and lactic acid bacteria)}

According to the currently adopted definition by the Food and Agriculture Organisation/World Health Organisation, probiotics are defined as "live microorganisms which when administered in adequate amounts confer a health benefit on the host" [15]. The original observation of the positive role played by certain bacteria was first introduced by Russian scientist and Nobel laureate Élie Metchnikoff, who in 1907 suggested that it would be possible to modify the gut flora by replacing harmful microbes with useful microbes. However, interest in the possible lipid lowering benefits of fermented milk, and the bacteria they contained, did not occur until later in the mid-1970 s when Mann and Spoerry [16] reported an $18 \%$ fall in plasma total cholesterol after feeding four to five litres of fermented milk/day for three weeks in 24 Maasi warriers. In a small follow-up study ( $n=$ four), Mann [17] reported that four litres/day of yoghurt (microbiological activity unspecified) over a 12 day period significantly reduced $(37 \%)$ serum total cholesterol. This was maintained when the intake was reduced to two litres/day, although not with one litre/day. It was suggested that this was due to a reduction in cholesterol biosynthesis possibly due to an unidentified 'milk factor' such as a HMG-CoA reductase inhibitor. Investigating possible candidates for the 'milk factor', Howard and Marks [18] fed lactose $\pm \mathrm{Ca} / \mathrm{Mg}$, cheese whey or yoghurt, to volunteers over a two week period. The yoghurt, but not the lactose $\pm \mathrm{Ca} / \mathrm{Mg}$ or cheese whey, significantly reduced plasma total cholesterol by $5.5 \%$ (Table 1). However, this trial was confounded by the lack of dietary control which resulted in substantial changes to the volunteers' habitual diet during the study.

Most of the early studies introduced confounding factors due to the lack of control of the subjects' diet, in addition to being underpowered, of short duration [19] and used exceptionally high volumes of intervention foods. In addition the relatively high milk/acidified milk used as the probiotic vehicle may have impacted on the results due to the potential effects of milk on satiety, food intake and other CVD risk marker such as blood pressure. In an attempt to control for these factors, Hepner et al. [20] performed a crossover study in which $720 \mathrm{ml}$ of yoghurt or milk were given each day to the subjects for a four week period. Significant reductions in plasma cholesterol were observed after the first week of both supplementation periods [20], suggesting that these changes may have been the consequence of participation in the study where conscious or even unconscious modification of the diet and other lifestyle factors is common, rather than a reflection of the bioactive properties of the intervention foods. A run-in period is often advised to counteract these effects [21]. Of the early negative studies that have been published, those of Thompson et al. [22], Massay [23] and McNamara et al. [24] incorporated a run-in period. The study performed by McNamara et al. [24] was one of the more carefully designed interventions. They investigated the effects of the ingestion of $480 \mathrm{ml}$ unspecified yoghurt in a study which included a three week run-in period and four week intervention period compared to a non-fermented milk concentrate (as a control). Dietary intake and body weight remained constant and there was no change in serum total, LDL-C, HDL-C or TAG levels [24]. In another well controlled, double blind, crossover study, Kefir ( $500 \mathrm{ml} /$ day) a fermented dairy product from the Balkans and Caucasus regions of Central Asia consumed for its potential health benefits, showed no lipid lowering properties when compared to unfermented milk [25]. From the studies mentioned above it can be concluded that there is little evidence 
K.G. Jackson and J.A. Lovegrove / Functional foods and lipid metabolism

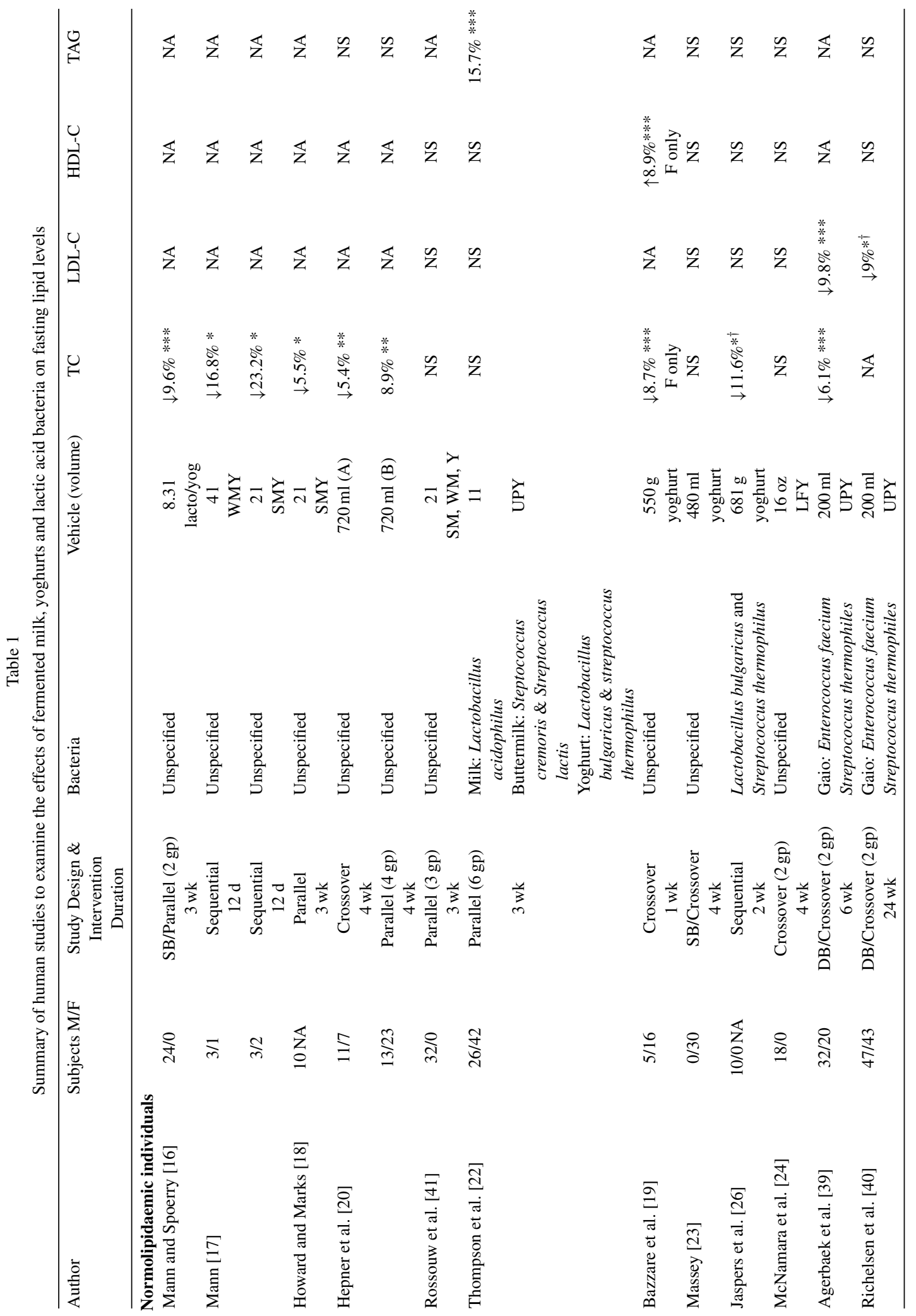




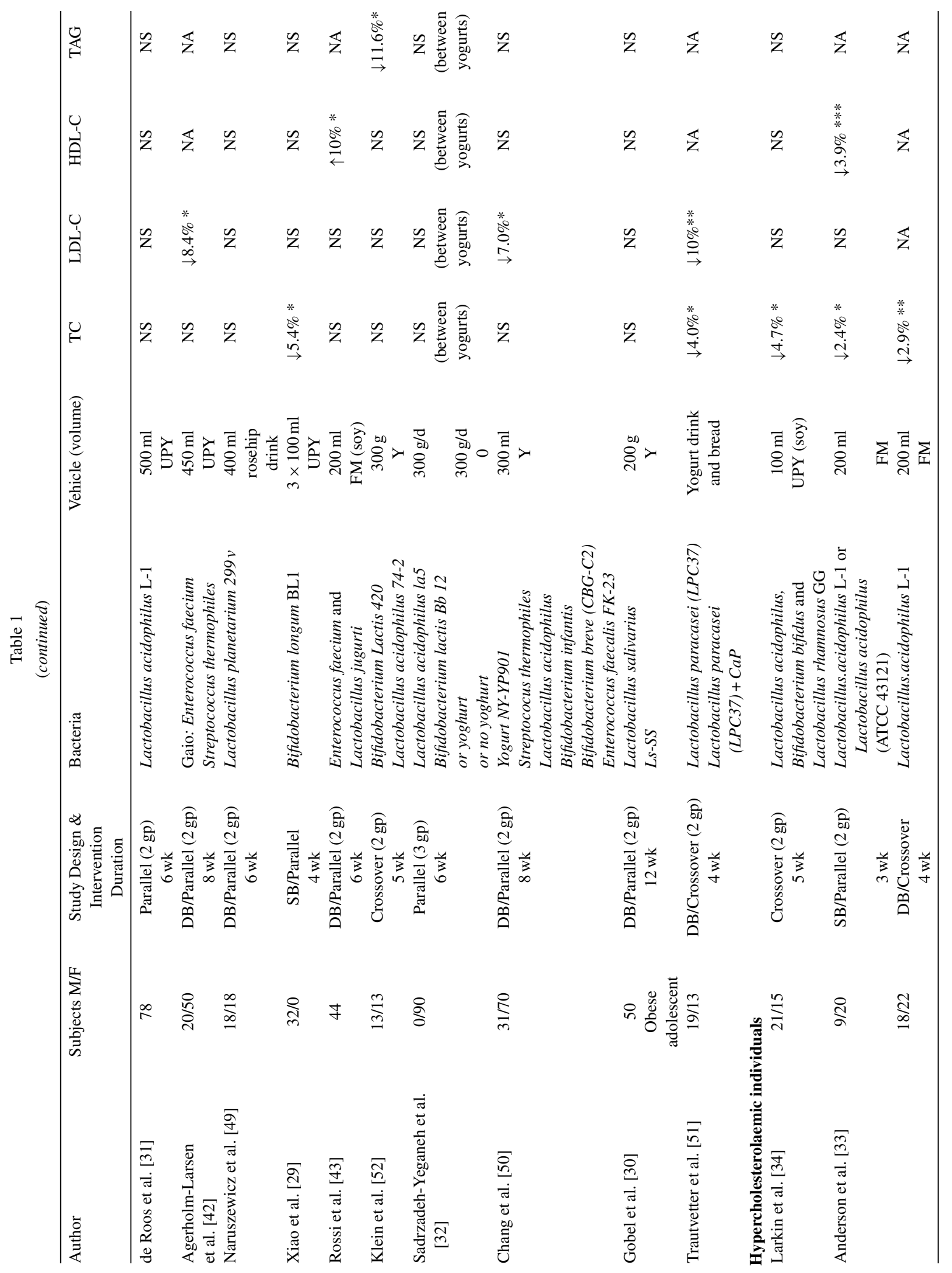




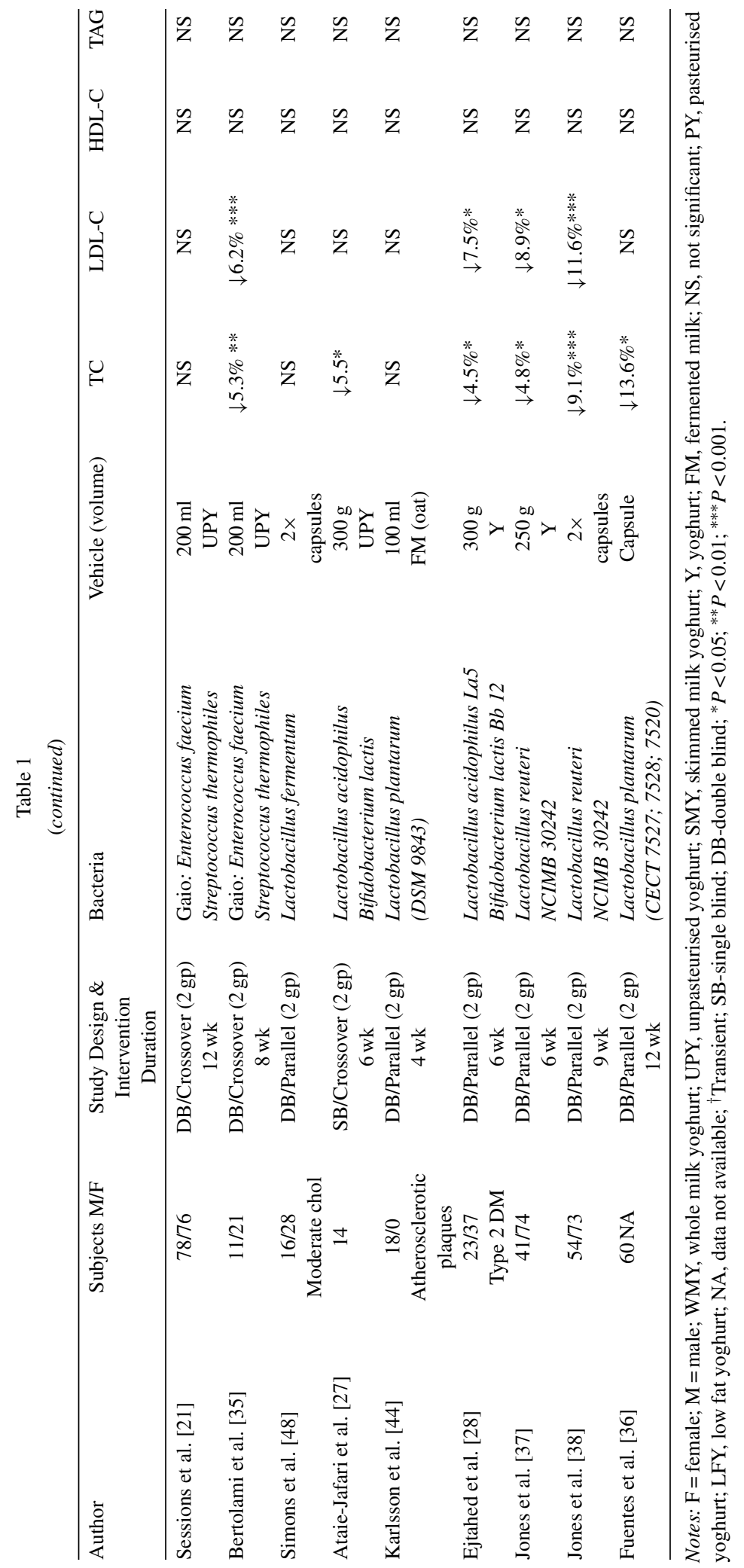


that fermented milk products per se affect serum lipid parameters.

\subsection{The effect of viable lactic acid bacteria on lipid parameters}

Hepner et al. [20] were the first to attempt to discern whether the presence of live bacteria was important for the reported affects of yoghurt on lipid parameters. The study compared the effects of $750 \mathrm{ml}$ of pasteurised and unpasteurised yoghurt, using milk as a placebo. After a 12 week intervention period all treatments significantly reduced plasma cholesterol levels, with milk resulting in a lesser reduction. Unfortunately, the nutritional and microbiological content of the products used was not reported, which severely hampers comparison with other study data. Thompson et al. [22] reported no effects of a wide range of milk based products (1 litre/day for 3 weeks) including milk supplemented with Lactobacillus acidophilus (undefined, strain code not given $-1.3 \times 10^{7}$ colony forming units (CFU) /ml), buttermilk (a milk product fermented with Streptococcus cremoris and Streptococcus lactis $-6.4 \times 10^{8} \times \mathrm{CFU} / \mathrm{ml}$ ) and a yoghurt (fermented with Lactobacillus bulgaricus and Streptococcus thermophilus $-1.2 \times 10^{9} \mathrm{CFU} / \mathrm{ml}$ ). The possible importance of variation in yoghurt cultures stimulated Jaspers et al. [26] to assess the effect of $681 \mathrm{~g} /$ day of three strains of a yoghurt fermented with a 1:1 ratio of Lactobacillus bulgaricus and Streptococcus thermophilus. CH-I and CH-II and SH-IIIA and SH-IIIB (species not given) taken for 14 days in a study of complex design. Body weight remained constant and dietary intake unchanged over the intervention period. Significant falls in serum total and LDL-C occurred after week one with the $\mathrm{CH}-\mathrm{II}$ strain and two weeks with the SH-IIIA strain, but these returned to baseline by the end of the study. These transient changes could be explained by the effect of commencing a study as discussed previously, or this could be a true difference between the efficacious properties of different strains. Latterly, well controlled studies using the probiotics Bifidobacterium longum $\mathrm{BL} 1$ (300 ml/day, $10^{8} \mathrm{CFU} / \mathrm{ml}$ ) for four weeks in normocholesterolaemic participants $(n=32)$ and Lactobacillus acidophilus with Bifidobacterium lactis (300 g/day) for six weeks in hypercholesterolaemic subjects with $(n=60)$ and without $(n=14)$ type 2 diabetes, resulted in significant hypocholesterolaemic effects [27-29] which probably reflected the efficacy of the particular probiotic bacteria present (Table 1). It has been proposed that the strain specific nature of probiotics is one of the critical issues when assessing probiotic efficacy with health associated activities, such as cholesterol reduction. An example of this is the differential health effects of Escherichia coli Nissle 1917 and Escherichia coli 0157. One is a safe and efficacious probiotic commercially available for nearly 100 years and the second a novel gastrointestinal pathogen. It is therefore of paramount importance to qualify the sub-species and strain of any probiotic. It is also worthy of note that the common approach of grouping all probiotic studies together as equal can often result in misleading conclusions.

The subject group studied also appears to be an important factor in the hypocholesterolaemic effects of lactic acid bacteria. A lack of effect was reported after obese adolescents $(n=50)$ consumed $200 \mathrm{~g} /$ day of a yoghurt with Lactobacillus salivarius $L s-S S$ for a 12 week period [30]. This was similar to De Roos and colleagues [31] and Sadrzadeh-Yeganeh and colleagues [32] who performed large studies $(n=78$ and 90 respectively) investigating the impact of $500 \mathrm{ml} /$ day of yoghurt supplemented with Lactobacillus acidophilus L-1 for a six week period in normocholesterolaemic subjects or $300 \mathrm{~g} /$ day of a probiotic yoghurt containing Lactobacillus acidophilus la5 and bifidobacterium lactis Bb12 compared with a conventional yogurt or no intervention (control) for a six week period [31, 32]. It was reported that there was no significant effect on any lipid parameters determined compared with the control yoghurt, although significant total and LDL-C lowering effects were reported by SadrzadehYeganeh and colleagues compared with no yoghurt [32]. This is in contrast to the studies by Anderson et al. [33] which investigated a smaller volume $(200 \mathrm{ml})$ of fermented milk (yoghurt-type) containing human Lactobacillus acidophilus L-1 or swine Lactobacillus acidophilus (ATCC 43121) in 40 hypercholesterolaemic subjects for a four week period and reported a significant reduction of $2.9 \%$ in total cholesterol compared with baseline. These data illustrate the importance of the cholesterol status of study participants on entry into the study. It is interesting to note that of the studies which investigated a variety of different probiotics in hypercholesterolaemic subjects seven out of nine (Table 1) reported a significant hypocholesterolaemic effect ranging from 2.4-13.6\% reduction [27, 28, 33-38], which is in contrast to the 
well controlled studies performed using normocholesterolaemic participants.

A number of studies have tested the lipid lowering effects of a particular probiotic yoghurt Gaio ${ }^{\circledR}$ (MD Foods Aarhus, Denmark) fermented by Causido ${ }^{\circledR}$ consisting of Enterococcus faecium (human species, undefined, strain code not given) and two strains of Streptococcus thermophilus with varying results. Agerbaek et al. [39] tested the effect of $200 \mathrm{ml}$ (Enterococcus faecium, $\sim 2 \times 10^{8} \mathrm{CFU} / \mathrm{ml}$ ) per day of Gaio ${ }^{\circledR}$ in a parallel study design, where the active yoghurt was tested against an identical yoghurt that had been chemically acidified with an organic acid (delta-glucolactone). The intervention was for a six week period in 58 middle-aged men with moderately raised cholesterol levels $(5.0-6.5 \mathrm{mmol} / \mathrm{l})$. They observed a $9.8 \%$ reduction in LDL-C levels for the live yoghurt group, which was sustained over the intervention period (Table 1). This was a well-controlled study, which excluded many variables such as age, sex and body weight. However, an unforeseen skew in the randomisation resulted in significantly different baseline total and LDL-C levels in the two groups. The fall in these parameters observed in the active yoghurt group could be ascribed to a regression towards the mean. Another study performed using the same yoghurt and a similar design for a longer period (six months) was carried out in 87 men and women aged between 50-70 years [40]. It was reported that at 12 weeks there was a significant drop in LDL-C levels in the group consuming the active yoghurt. These reductions were not sustained and this was partly explained by a reduction in the numbers of viable bacteria (Enterococcus faecium) in the yoghurt at 12 weeks. At the end of the study, no significant reductions in total or LDL-C levels were observed between the two groups. Using a randomised, double-blind placebo controlled study, Bertolami and colleagues investigated the effects of consuming $200 \mathrm{~g} /$ day of the same yoghurt in 32 patients who had mild to moderate hypercholesterolaemia. The patients were asked to follow a lipid-lowering diet for eight weeks and were then given the test or control product for two eight week periods. The results showed a significant reduction of $10.3 \%$ for total cholesterol and a $6.2 \%$ reduction in LDL-C levels after the active product. However, the authors did question whether or not the average reduction of approximately $5 \%$ for total and LDL-C was clinically significant [35].

A similar trial of the same Gaio ${ }^{\circledR}$ product containing Enterococcus faecium was conducted in 160 middle-aged men and women with moderately raised cholesterol [21]. The study was a randomised, doubleblind, multi-centre, placebo controlled parallel study and was the largest performed to date. Volunteers consumed $200 \mathrm{ml} /$ day of either the active or chemically acidified yoghurt for a 12 week period. Stratified randomisation was used to ensure that the groups were comparable for age, sex, BMI and baseline fasting cholesterol levels. The importance of not changing their dietary habits and lifestyle during the study was emphasised to the volunteers and adherence to the protocol confirmed by dietary assessment. The levels of Enterococcus faecium in the active yoghurt were monitored throughout the study and found to be no lower than $1 \times 10^{6} \mathrm{CFU} / \mathrm{ml}$ at any time tested. During the two-week run-in period, both groups showed significant reductions in plasma cholesterol levels, but thereafter there were no further changes in either of the groups or between the groups at any of the time points. These data do not support previous studies discussed, but are consistent with the conclusions drawn by Rossouw et al. [41] regarding cholesterol changes attributed to study participation. In summary, six published studies (Table 1) have investigated whether the addition of Gaio $^{\circledR}$ to the habitual diet can reduce plasma cholesterol. Four studies showed a small beneficial short-term effect of a 6-10\% reduction of LDL-C $[35,39,40,42]$, yet the long-term effects were inconclusive [40] with the largest study to date failing to show any significant effects [21]. However despite these inconsistent reports, a meta-analysis of these studies has concluded that both total and LDL-C was reduced by $6 \%$ and $9 \%$ respectively compared to the control yoghurt and provides evidence for a short-term beneficial effect of Gaio ${ }^{\circledR}$ [42].

The majority of the studies investigating the effect of lactic acid bacteria and probiotics have used fermented cow's milk or cow's milk yoghurt. In contrast, two studies have determined the effect of fermented soy milk [43] and soy milk consumed with a probiotic yoghurt [34] on lipid concentrations with conflicting results, and one study using fermented oat milk [44]. Although there are discrepancies in relation to the particular components of soy that are active, there is increasing evidence that soy consumption is related to a reduction in plasma lipids [45]. Isoflavones alone generally do not reduce lipids [46] yet in combination with soy proteins appear to be beneficial $[45,47]$. Consequently the impact of the addition of a probiotic to soy products on lipid-lowering effects of these products was 
investigated. Rossi and colleagues [43] determined the impact of the addition of $200 \mathrm{ml} /$ day of fermented soy milk produced with Enterococcus faecium (undefined, strain not given) and Lactobacillus jugurti (undefined, strain not given) for a six week period in normocholesterolaeimic middle-aged men. Despite containing isoflavones, soy protein and the same species as Gaio (Enterococcusfaecium) this fermented soy milk did not significantly affect the total or LDL-C levels, but did result in a $10 \%$ increase in HDL-C [43]. These data are in contrast to the observations of a study which investigated the effect of soy milk and either $100 \mathrm{ml}$ probiotic yoghurt (containing $10^{8} \mathrm{CFU} /$ serving of each of Lactobacillus acidophilus (undefined, strain not given), Bifidobacterium bifidus (undefined, strain not given), and Lactobacillus rhamnosus GG) or yoghurt containing typical yoghurt starter cultures. It was reported that the dietary combination of soy with probiotic yoghurt resulted in a significant reduction in total cholesterol $(-4.7 \%)$ and potential synergistic hypocholesterolaemic actions between soy and probiotic bacteria were suggested [34]. In another study, $100 \mathrm{ml}$ of fermented oat milk containing Lactobacillus plantarum (DSM 9843, $10^{11} \mathrm{CFU} / \mathrm{ml}$ ) was consumed in a double blind parallel study in 18 men with atherosclerotic plaques. Although it was reported that there was a significant increase in plasma short chain fatty acids (SCFAs) and colonic bacterial diversity, there was no significant impact on lipid concentrations compared to a control product [44].

Probiotics can also be given in the form of capsules rather than in milk or yoghurts. A study performed in 60 hypocholesterolaemic participants investigated the impact of different strains (CECT 7527, 7528 and 7520) of Lactobacillus plantarum $\left(1.2 \times 10^{9} \mathrm{CFU}\right)$ contained within a capsule, compared with a placebo capsule containing no bacteria. A significant reduction of $13.6 \%$ in plasma total cholesterol was observed after 12 weeks. However the degree of reduction was dependent on the baseline cholesterol concentrations. Participants with high cholesterol ( $>6.5 \mathrm{mmol} / \mathrm{l}$ ) had a greater total and LDL-C reduction compared with those with lower baseline cholesterol concentrations [36]. This impact of baseline cholesterol concentrations may have explained the lack of effect of capsules (two/day) containing Lactobacillus fermentum $\left(2 \times 10^{9} \mathrm{CFU} /\right.$ capsule $)$ in moderate hypercholesterolaemic subjects [48], and in a study investigating a rosehip drink $(400 \mathrm{ml} /$ day) containing Lactobacillus plantarum $299 v\left(5 \times 10^{7} \mathrm{CFU} / \mathrm{ml}\right)$ in normocholesterolaemic participants [49]. Another method of probiotic delivery is that of microencapsulation, which allows determination of the impact of the probiotic, without the confounding effects of other potentially bioactive components present in the food vehicle. Two studies published by Jones and colleagues have reported significant reductions in total $(4.8 \%$ and $9.1 \%)$ and LDL-C ( $8.9 \%$ and $11.6 \%)$ by microencapsulated Lactobacillus reuteri NCIMB 30242 in the form of yoghurt $(250 \mathrm{~g} / \mathrm{d})$ or capsules (two daily) for a six and nine week period in hypercholesterolaemic subjects ( $n=114$ and 127) respectively [37, 38]. They proposed that the beneficial effects reported were due to an increased number of viable probiotic reaching the colon, facilitated by the microencapsulation, in addition to consuming high quantities $\left(10^{9} \mathrm{CFU}\right)$ of the probiotic bacteria daily [37, 38].

From the findings available to date, it can be concluded that there is evidence to support a hypocholesteraemic effect of a daily consumption of some lactic acid bacteria containing products, which is more apparent in those with hypercholesterolaemia. The most consistent finding is a reduction in total cholesterol, which is associated with a significant LDL-C reduction in some [35, 37-42, 50, 51], but not all studies, although some of these studies were confounded by weight reduction [50]. However only one of the studies that have measured plasma TAG (see Table 1) have reported a significant reduction $(11.6 \%)$ in this lipid level [52], with another study reporting a significant increase of $16 \%$ [22]. A current meta-analysis of randomised controlled trials investigating the effect of probiotics on plasma lipid profiles concluded that a pooled analysis of 13 trials ( $n=485$ participants) with high, borderline or normal cholesterol concentrations suggested mean net changes in total, LDL-C and HDL-C of $-0.17,-0.13$ and $-0.003 \mathrm{mmol} / 1 \mathrm{respec}-$ tively and for TAG $-0.04 \mathrm{mmol} / 1$ [53]. Therefore it is apparent that the impact of probiotic bacteria on CHD lipid risk reduction is in their potential hypocholesterolaemic effects. However results are inconsistent particularly in normocholesterolaemic groups and further suitably powered and well-controlled studies are required to determine the impact of specific probiotic strains.

\subsection{Possible mechanisms of action of lactic acid bacteria}

Before the possible mechanisms are considered, it is important to highlight that since viable and 
biologically active micro-organisms are usually required at the target site in the host, it is essential that the probiotics not only have the characteristics that are necessary to produce the desired biological effects; but also have the required viability and are able to withstand the host's natural barriers against ingested bacteria. The classic yoghurt starter bacteria, Streptococcus thermophilus and Lactobacillus bulgaricus are technologically effective, but they do not reach the lower intestinal tract in a viable form. Therefore, intrinsic microbiological properties, such as tolerance to gastric acid, bile and pancreatic juice are important factors when probiotic organisms are considered [54].

The mechanism of action of lactic acid bacteria and probiotics on cholesterol reduction is unclear, but there are a number of proposed possibilities which may act independently or synergistically. These include physiological actions of the end products of fermentation SCFA; cholesterol assimilation, deconjugation of bile acids and cholesterol binding to bacterial cell walls. The SCFA that are produced by the bacterial anaerobic breakdown of carbohydrate are acetate, propionate and butyrate. The physiological effects of these are discussed in detail in the Section 3.2.

It has been well documented that microbial bile acid metabolism is a peculiar effect involved in the therapeutic role of some bacteria. The deconjugation reaction is catalysed by conjugated bile acid hydrolase enzyme, which is produced exclusively by bacteria [55]. Deconjugation ability is widely found in many intestinal bacteria including genera Enterococcus, Peptostreptococcus, Bifidobacterium, Fusobacterium, Clostridium, Bacteroides and Lactobacillus [56]. This reaction liberates the amino acid moiety and the deconjugated bile acid thereby reducing cholesterol re-absorption, by increasing faecal excretion of the deconjugated bile acids. Many in vitro studies have investigated the ability of various bacteria to deconjugate a variety of different bile acids. Grill et al. [57] reported Bifidobacterium longum strains (BB536 and OC) as the most efficient bacterium among four Bifidobacterium strains (Bifidobacterium animalis; Bifidobacterium infantis; Bifidobacteriu brev and Bifdobacterium thermophilum) when tested against six different bile salts. Another study reported that Lactobacillus species had varying ability to deconjugate glycocholate and taurocholate [58] with Lactobacillus fermentum $\mathrm{KC} 5 \mathrm{~b}$ reported to have the ability to deconjugate a number of bile salts in vitro [59]. Studies performed on in vitro responses are useful, but in vivo studies in animals and humans are required to determine the full contribution of bile acid deconjugation to cholesterol reduction. Intervention studies in animals and ileostomy patients have shown that oral administration of certain bacterial strains led to an increased excretion of free and secondary bile salts $[29,60,61]$. Of particular note are the studies of Jones et al. [37, 38] and Fuentes [36] in which probiotic strains were chosen for their specific bile acid deconjugation activities. As described previously Jones et al. [38] and Fuentes et al. [36] reported consumption of the probiotic Lactobacillus reuteri NCIMB 30242 and three strains of Lactobacillus plantarum (CECT 7527, CECT 7528 and CECT 7529) respectively in microencapsulated form, resulted in significant LDL-C reduction. It was proposed this was due to a reduction in lipid uptake from the gut [36-38], which was supported by the elevated plasma deconjugated bile acid concentrations which affect endogenous hepatic cholesterol metabolism [38]. It was stated by the Jones and colleagues that Lactobacillus reuteri NCIMB 30242 appeared to be superior to traditional probiotic therapy and akin to that of other cholesterol-lowering ingredients. These studies highlight the importance of probiotic selection for efficacious hypocholesterolaemic effects.

There is also some in vitro evidence to support the hypothesis that certain bacteria can assimilate (take up) cholesterol [62]. It was reported that Lactobacillus acidophilus (RP32) [58], Bifidobacterium bifidum (strains BYU and BPO) [63], Lactobacillus fermentum (KC5b) [64] had the ability to assimilate cholesterol in in vitro studies, but only in the presence of bile and under anaerobic conditions. However, despite these reports, there is uncertainty whether the bacteria are assimilating cholesterol or whether the cholesterol is co-precipitating with the bile salts. Studies have been performed to address this question. Klaver and Meer [65] concluded that the removal of cholesterol from the growth medium in which Lactobacillus acidophilus (RP32) and a Bifidobacterium (MUH80) were growing was not due to assimilation, but due to bacterial bile salt deconjugase activity. The same question was addressed by Tahri et al. [66] with conflicting results, and they concluded that part of the removed cholesterol was found in the cell extracts and that cholesterol assimilation and bile acid deconjugase activity could occur simultaneously.

The mechanism of cholesterol binding to bacterial cell walls has also been suggested as a possible 
explanation for hypocholesterolaemic effects of probiotics. Hosona and Tono-oka [67] reported that Lactococcus lactis subsp. Biovar. Diacylactis $R-43 \mathrm{had}$ the highest binding capacity for cholesterol of bacteria tested in the study. Lin and Chen [68] after investigating the in vitro cholesterol reducing abilities of six Lactobacillus acidophilus strains reported that the in vivo hypocholesterolaemic effects of these bacterial cells was due to the direct assimilation by the cells and/or attachment of cholesterol to their surface. It was speculated that the binding differences were due to chemical and structural properties of the cell walls, and that even killed cells may have the ability to bind cholesterol in the intestine. The mechanism of action of probiotics on cholesterol reduction could be one or all of the above mechanisms with the ability of different bacterial species to have varying effects on cholesterol lowering. However more research is required to fully elucidate the effect and mechanism of probiotics and their possible hypocholesterolaemic action.

\section{Prebiotics}

Over the past three decades, there has been increasing interest in the important nutritional role of prebiotics as functional food ingredients. This interest has been derived from animal studies which showed markedly reduced TAG and total cholesterol levels when diets containing significant amounts of a prebiotic (oligofructose (OFS)) were fed. A prebiotic is defined as 'a selectively fermented ingredient that results in specific changes, in the composition and/or activity of the gastrointestinal microbiota, thus conferring benefit(s) upon host health' [69]. Prebiotics, most often referred to as non-digestible oligosaccharides, are extracted from natural sources (e.g. inulin and OFS) or synthesised from disaccharides (e.g. transgalactooligosaccharides). The most commonly studied of the prebiotics include inulin and OFS which are found in many vegetables, including onion, garlic, leek, asparagus, Jerusalem artichoke and chicory root [70]. These consist of between two and sixty fructose molecules joined by $\beta 2-1$ osidic linkages, which, due to the nature of this type of linkage escape digestion in the upper gastrointestinal tract and remain intact but are selectively fermented by colonic microbiota. Inulin is currently found as a food ingredient of bread, baked goods, yoghurt and ice-cream because it displays gelling and thickening properties and helps to improve the mouth feel and appearance of lower energy products [70]. In Europe, the estimated intake of inulin and OFS is between three and $12 \mathrm{~g}$ per day [71].

\subsection{The effect of prebiotics on lipid metabolism in humans}

Twenty-one studies have investigated the effects of prebiotics on fasting plasma lipids [72-92], but findings have been inconsistent (Table 2). In the eight studies with individuals with moderated raised lipids and hyperlipidaemia, one study showed a reduction in fasting total, LDL-C and TAG [90], four studies showed significant decreases in fasting total and/or LDL-C with no changes in TAG levels [85-88] whereas two studies showed a significant reduction in fasting TAG only [73, 89]. In contrast, of the three studies conducted in type II diabetics, only one study reported significant reductions in total and LDL-C [91] (Table 2). In normolipidaemic participants, four out of the ten studies have reported an effect on fasting lipid concentrations $[75,79,81,83]$. One study found reductions in total and LDL-C only (6-8\%) [83], whereas the remaining three studies all showed reductions in fasting TAG levels (16-27\%) [75, 79, 81]. Of these studies, one also reported a reduction in total cholesterol $(8 \%)$ [75] whereas Russo et al. [81] also demonstrated a concomitant increase in HDL-C. In the study by Jackson et al. [73], follow-up blood samples were taken four weeks after completion of the inulin supplementation period by which time the concentrations of TAG had returned to baseline values, supporting the conclusion that inulin feeding may have been responsible. A metaanalysis of 15 randomised controlled trials (conducted between 1996 and 2005) has reported that inulin-type fructans can significantly decrease fasting TAG concentrations by $0.17 \mathrm{mmol} / 1$ [93]. These findings are in line with observed effects of inulin on lipid levels in animals in which the predominant effect is on TAG rather than cholesterol concentrations.

Data from studies in rats have shown a $40 \%$ reduction in postprandial TAG concentrations when diets containing ten per cent OFS (w/v) were fed [94]. However, very little information regarding the effect of prebiotics on postprandial lipaemia in human subjects are available, with two studies reporting a lack of effect of inulin treatment on postprandial TAG levels in middle-aged men and women with moderately raised lipids $[73,84]$. 
Table 2

Summary of human studies to examine the effects of fructan supplementation on fasting lipid levels

\begin{tabular}{|c|c|c|c|c|c|c|c|c|}
\hline \multirow[t]{2}{*}{ Author } & \multirow{2}{*}{$\begin{array}{r}\text { Subjects } \\
(\mathrm{M} / \mathrm{F})\end{array}$} & \multirow{2}{*}{$\begin{array}{l}\text { Study design and } \\
\text { duration }\end{array}$} & \multirow[t]{2}{*}{ Fructan and dose } & \multirow[t]{2}{*}{ Vehicle } & \multicolumn{4}{|c|}{ Change observed in: } \\
\hline & & & & & TC & LDL-C & HDL-C & TAG \\
\hline \multicolumn{9}{|c|}{ Normolipidaemic individuals } \\
\hline Pedersen et al. [74] & $0 / 66$ & DB, crossover 4 wks & inulin $14 \mathrm{~g}$ & margarine & NS & NS & NS & NS \\
\hline Brighenti et al. [75] & $12 / 0$ & Sequential 4 wks & inulin $9 \mathrm{~g}$ & $\begin{array}{c}\text { breakfast } \\
\text { cereal }\end{array}$ & $\downarrow 8 \%$ & NS & NS & $\downarrow 21 \%$ \\
\hline Kruse et al. [76] & $6 / 5$ & $\mathrm{DB}$, parallel $9 \mathrm{wks}$ & inulin $22-34 \mathrm{~g}$ & yoghurt & NS & NS & NS & NS \\
\hline van Dokkum et al. [77] & $12 / 0$ & $\mathrm{DB}$, crossover 3 wks & inulin, OFS or GOS $15 \mathrm{~g}$ & orange juice & NS & NS & NS & NS \\
\hline Luo et al. [78] & $12 / 0$ & $\mathrm{DB}$, crossover 4 wks & OFS $20 \mathrm{~g}$ & biscuits & NS & NS & NS & NS \\
\hline Letexier et al. [79] & $4 / 4$ & $\mathrm{DB}$, crossover $3 \mathrm{wks}$ & Inulin $10 \mathrm{~g}$ & sachet & NS & NS & NS & $\downarrow 16 \%$ \\
\hline Forcheron et al. [80] & $6 / 11$ & $\mathrm{DB}$, crossover 24 wks & inulin/ OFS $10 \mathrm{~g}$ & sachet & NS & NS & NS & NS \\
\hline Russo et al. [81] & $22 / 0$ & DB, crossover 5 wks & inulin $11 \mathrm{~g}$ & pasta & NS & NA & $\uparrow 36 \%$ & $\downarrow 23 \%$ \\
\hline Vulevic et al. [82] & $16 / 28^{\S}$ & $\mathrm{DB}$, crossover $10 \mathrm{wks}$ & GOS $5.5 \mathrm{~g}$ & sachet & NS & NA & NS & N/A \\
\hline de Luis et al. [83] & $4 / 26$ & DB, parallel 4 wks & inulin $3 \mathrm{~g}$ & biscuits & $\downarrow 6 \%$ & $\downarrow 8 \%$ & NS & NS \\
\hline \multicolumn{9}{|c|}{ Moderately hyperlipidaemic individuals } \\
\hline Jackson et al. [73] & $27 / 27$ & DB, parallel 8 wks & inulin $10 \mathrm{~g}$ & sachet & NS & NS & NS & $\downarrow 19 \%$ \\
\hline Giacco et al. [84] & $20 / 10$ & $\mathrm{DB}$, crossover 8 wks & OFS $5.3 \mathrm{~g}$ & sachet & NS & NS & NS & NS \\
\hline Genta et al. [85] & $0 / 35$ & DB, parallel 16 wks & OFS $10 \mathrm{~g}$ & syrup & NS & $\downarrow 27 \%$ & NS & NS \\
\hline Yen et al. [86] & $6 / 4^{\S}$ & DB, parallel 3 wks & OFS $5-10 \mathrm{~g}$ & sachet & $\downarrow 7 \%$ & NA & NA & NS \\
\hline \multicolumn{9}{|c|}{ Hyperlipidaemic individuals } \\
\hline Hidaka et al. [87] & $20 / 26$ & DB, parallel 5 wks & OFS $8 \mathrm{~g}$ & confectionary & $\downarrow 6 \%$ & NA & NS & NS \\
\hline Davidson et al. [88] & $12 / 13$ & $\mathrm{DB}$, crossover $6 \mathrm{wks}$ & inulin $18 \mathrm{~g}$ & $\begin{array}{l}\text { chocolate bar, } \\
\text { paste or } \\
\text { sweetner }\end{array}$ & $\downarrow 9 \%$ & $\downarrow 14 \%$ & NS & NS \\
\hline Causey et al. [89] & $12 / 0$ & $\mathrm{DB}$, crossover $3 \mathrm{wks}$ & inulin $20 \mathrm{~g}$ & $\begin{array}{l}\text { low fat } \\
\text { ice-cream }\end{array}$ & NS & NS & NS & $\downarrow 14 \%$ \\
\hline Balcázar-Munoz et al. [90] & $12 / 0$ & DB, parallel $4 \mathrm{wks}$ & inulin $7 \mathrm{~g}$ & not specified & $\downarrow 22 \%$ & $\downarrow 17 \%$ & NS & $\downarrow 27 \%$ \\
\hline \multicolumn{9}{|l|}{ Type II diabetics } \\
\hline Yamashita et al. [91] & $8 / 10$ & DB, parallel 2 wks & OFS $8 \mathrm{~g}$ & $\begin{array}{l}\text { coffee drink or } \\
\text { jelly }\end{array}$ & $\downarrow 8 \%$ & $\downarrow 10 \%$ & NS & NS \\
\hline Alles et al. [72] & $9 / 11$ & $\mathrm{SB}$, crossover $3 \mathrm{wks}$ & OFS $15 \mathrm{~g}$ & not specified & NS & NS & NS & NS \\
\hline Luo et al. [92] & $6 / 4$ & DB, crossover 4 wks & OFS $20 \mathrm{~g}$ & sachet & NS & NS & NS & NS \\
\hline
\end{tabular}

Abbreviations: DB, double blind; F, female; GOS, galacto-oligosaccharide; HDL-C, high density lipoprotein cholesterol; M, male; NA, not analysed; NS, not significant; SB, single blind; TC, total cholesterol; LDL-C, low density lipoprotein cholesterol; OFS, oligofrucose; TAG, triacylglycerol. ${ }^{\S}$ elderly subjects.

The marked reductions in fasting lipid levels observed in animal studies have not been consistently reproduced in human subjects. This may be explained by the amount of fructans used in the human studies which varies between 5-20 g, with a single study using $34 \mathrm{~g}$ (Table 2). This amount is small compared to that used in animal studies (50-200 g/day OFS of rat chow) [95] which is equivalent to a dose in humans of approximately $50-80 \mathrm{~g}$ of OFS/inulin per day. The fact that OFS and inulin are fibres restricts its dosage in humans to between 15-20 g per day, with intakes greater than this associated with gastrointestinal symptoms such as stomach cramps, flatulence and diarrhoea $[74,85]$. However, some studies have shown tolerance of higher amounts of prebiotics by increasing the daily dose (22.8 g to $45.6 \mathrm{~g}$ ) slowly over a number of weeks
[96], and also by consuming higher doses (22-34 g) with a low-fat, high carbohydrate diet $(30 \%$ energy fat, $55 \%$ carbohydrate and $15 \%$ protein) [76]. One acute postprandial study also reported the lack of gastrointestinal symptoms when $48 \mathrm{~g}$ of resistant starch (a fermentable carbohydrate) was split over two meals, with $24 \mathrm{~g}$ given with the breakfast and lunch $5 \mathrm{~h}$ later [97]. These studies indicate that it may be possible to introduce higher intakes of fermentable fibre into the Western-style diet in a tapered fashion thereby avoiding the reported bloating and flatulence associated with single doses of inulin and OFS given in powder form. Higher fibre intakes between 70-120 g/day have been observed in populations following traditional diets rich in fruits, vegetables and grains and also our ancestral hunter-gathers, suggesting that greater 
intakes of fermentable fibres may be possible in the diet [98]. At present, it is not known whether, at the levels used in human studies, significant effects on fasting lipid levels would also be observed in animals [99].

The types of food vehicles used to increase the amount of fructans (OFS, galacto-oligosaccharides and inulin) in the diet differ. In the case of Luo et al. [78] $100 \mathrm{~g}$ of biscuits were eaten every day and for Pedersen et al. [74], $40 \mathrm{~g} /$ day of margarine was consumed which may have contributed to the negative findings in blood lipids. In the case of Davidson et al. [88], significant changes in total and LDL-C levels were observed over six weeks with inulin in comparison with the placebo (sugar) incorporated into a number of study products including a chocolate bar, a chocolate spread and sweeteners for coffee or fruit. The percentage change in each of the lipid parameters was calculated over each of the six week treatment periods and unexpectedly, there was an increase in total cholesterol, LDL-C and TAG during the placebo phase. Non-significant falls in these variables were observed during inulin treatment and so when the net changes in the variables were calculated (change during inulin treatment minus change during control treatment) there were significant differences in total and LDL-C between the two treatments. The authors attributed the increase in total and LDL-C levels in the placebo phase to be due to the increased intake of saturated fatty acids in the chocolate products which were used as two of the vehicles in the study [88]. In later studies, the use of inulin in a powder form has enabled it to be added to many of the foods eaten in the participant's normal diet without any need for dietary advice thus avoiding changes in body weight. Since inulin has water binding properties, in its powder form inulin could be added to orange juice, tea, coffee, yoghurt and soup [73, 79, 80, 82, 84, 86, 90].

The significant relationship between the participants initial TAG concentration and percentage change in TAG levels over the eight week study demonstrated by Jackson et al. [73] lends support to the hypothesis that the initial TAG levels could be important in determining the degree of the TAG response to inulin. The lack of response in some individuals may be as a result of them being less responsive to inulin, variations in their background diet, or non-compliance with the study protocol. Speculation as to possible reasons for variability in response would be aided by a better understanding of the mechanism of action of inulin on plasma TAG levels.
The length of the supplementation period used in the studies in Table 2 may be another factor for the inconsistent changes in TAG levels in human subjects with inulin. The studies were conducted over two to 24 weeks, with significant effects occurring as early as three to four weeks $[75,79,83,89,90]$. One study conducted for 24 weeks showed no effect of inulin/OFS on lipid levels in normolipidaemic participants [80], suggesting that beneficial effects observed in the shortterm studies may not persist on a long-term basis. A wash out period of four weeks has been shown to be a sufficient period time for the TAG concentrations to return to baseline values [73]. This may provide an explanation for the significant findings in TAG levels in the studies of Causey et al. [89] and Brighenti et al. [75] who used three to four week sequential and crossover designs with very short wash out periods.

Whilst some of the studies, to date, support beneficial effects of inulin on plasma TAG, the findings are by no means consistent and more work is required to provide convincing evidence of the lipid lowering consequences of prebiotic ingestion.

\subsection{Mechanism of lipid lowering by prebiotics}

Prebiotics have been shown to be an ideal substrate for the health promoting bacteria in the colon, notably bifidobacteria and lactobacilli [100]. During the fermentation process a number of by-products are produced including gases $\left(\mathrm{H}_{2} \mathrm{~S}, \mathrm{CO}_{2}, \mathrm{H}_{2}, \mathrm{CH}_{4}\right)$, lactate and SCFAs (acetate, butyrate and propionate). The SCFAs, acetate and propionate enter the portal blood stream where they are utilised by the liver. Acetate is converted to acetyl CoA in the liver and acts as a lipogenic substrate for de novo lipogenesis, whereas propionate has been reported to inhibit lipid synthesis [101, 102]. Butyrate, on the other hand, is taken up by the large intestinal cells (colonocytes) and has been shown to protect against tumour formation in the gut [103]. The type of SCFAs which are produced during the fermentation process is dependent on the microbiota which can be stimulated by the prebiotic. In vitro fermentation experiments have shown inulintype fructans to increase both acetate and butyrate levels, whereas galacto-oligosaccharides and xylooligosaccharides increase. Synthetically produced prebiotics, for example galacto-oligosaccharides and xylo-oligosaccharides increase the production of acetate, propionate and butyrate [103-105]. 
Interestingly, Kabel et al. [104] demonstrated that these SCFA were produced at different stages of the fermentation of xylo-oligosaccharides, with the first stage $(0-40 \mathrm{~h})$ associated with a marked production of acetate whereas the later stage $(>40 \mathrm{~h})$ propionate and butyrate production predominated. These differences may reflect the type of bacteria involved in the early and later stages of the fermentation process.

Inulin and OFS have been extensively studied to determine the mechanism of action of prebiotics in animals. Early in vitro studies using isolated rat hepatocytes suggested that the hypolipidaemic action of OFS was associated with the inhibition of de novo cholesterol synthesis by the SCFA propionate following impairment of acetate utilisation by the liver for de novo lipogenesis [102]. This is in agreement with human studies in which rectal infusions of acetate and propionate resulted in propionate inhibiting the incorporation of acetate into TAGs released from the liver [106]. Fiordaliso et al. [107] demonstrated significant reductions in plasma TAGs, phospholipids and cholesterol in normolipidaemic rats fed a rat chow diet containing ten per cent (w/v) OFS. The TAGlowering effect was demonstrated after only one week of OFS and was associated with a reduction in the secretion of very low density lipoprotein (VLDL) from the liver. The reduction observed in cholesterol levels in the rats was only demonstrated after long term feeding (16 weeks) of OFS. Interestingly, in healthy men and women, ingestion of $10 \mathrm{~g}$ of inulin for three weeks led to reduced hepatic lipogenesis and fasting TAG level with no significant effects on plasma cholesterol concentrations [79]. The TAG-lowering effect of OFS is suggested to occur via reduction in VLDL TAG secretion from the liver due to the reduction in activity of all lipogenic enzymes (acetyl-CoA carboxylase, fatty acid synthase, malic enzyme, ATP citrate lyase and glucose-6-phosphate dehydrogenase), and in the case of fatty acid synthase, via modification of lipogenic gene expression [108] (Fig. 1). However, a recent animal study has reported different mechanisms of action of two fermentable fibres on beneficial metabolic effects observed after supplementation of a high-fat diet with $10 \%(\mathrm{w} / \mathrm{w})$ insulin or $\beta$-glucan for eight weeks [109]. Although both inulin and $\beta$-glucan were protective against weight gain, inulin was shown to mediate this effect via a reduction in body adiposity whereas $\beta$-glucan was shown to reduce food consumption. These findings are intriguing and indicate that prebiotics can no longer be considered to be all the

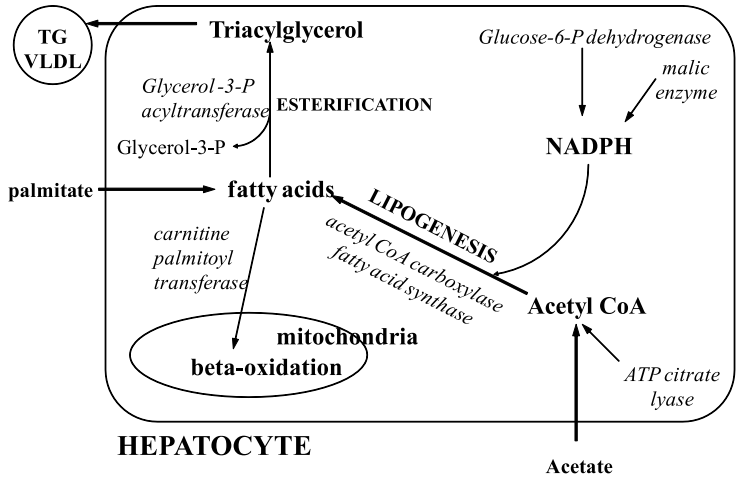

Fig. 1. Hepatic fatty acid metabolism. Adapted from Delzenne and Kok [108]. Abbreviations: TAG, triacylglycerol; VLDL, very low density lipoprotein.

same. This may provide an explanation for the variability in the lipid response observed in the human studies.

In summary, the mechanisms of action of prebiotics, especially inulin and OFS, have been determined largely from animal studies. Present data suggest inhibition of de novo lipogenesis as the primary mode of action of prebiotics in mediating their lipid lowering effects via down regulation of the enzymes involved. If this is the case, more modest or inconsistent effects might be expected in humans, in whom de novo lipogenesis is extremely low, or variable depending on their background diet. In animal studies, rats are fed a diet which is low in fat and high in carbohydrate and so de novo lipogenesis is an upregulated pathway in these animals for the synthesis of fatty acids. It is interesting to note that when rats are fed OFS along with a high fat diet typical of the Western-style diet, TAG levels are thought to be decreased by a different mechanism involving the enhanced clearance of TAG-rich lipoproteins. An increased secretion of glucose-dependent insulinotrophic polypeptide (GIP) in OFS treated rats was observed by Kok et al. [94] and this gut hormone has been shown to enhance the activity of lipoprotein lipase, the principal enzyme involved in the clearance of TAG-rich lipoproteins following the ingestion of fat [110]. The release of GIP and GLP-1 in the intestine and colon may act as mediators of the systemic effect of prebiotics such as inulin and OFS, on blood lipid concentrations. However, further work is required to determine the metabolic pathways which are influenced by different prebiotic preparations. Their effect on gastrointestinal kinetics such as gastric emptying and its modification of the levels of TAG-rich lipoproteins (chylomicrons and VLDL) in the circulation has 
recently been proposed as a potential modulator of systemic effects [111]. Therefore, the design of future studies to investigate the effect of prebiotics in humans should consider the choice of prebiotic, subject group, length of supplementation period and type of vehicle used to increase the intake of prebiotics in the diet, as these variables may influence the outcome of the study.

\section{Synbiotics (including combinations of lactic acid bacteria and prebiotic fibres)}

A synbiotic is defined as 'a mixture of a prebiotic and a probiotic that beneficially affects the host by improving the survival and the implantation of live microbial dietary supplements in the gastrointestinal tract, by selectively stimulating the growth and/or by activating the metabolism of one or a limited number of health promoting bacteria' [112]. The use of synbiotics (or other combinations of lactic acid bacteria and fibres) as functional food ingredients is a developing research area and only six human studies have been performed looking at their effects on lipid metabolism (Table 3). In normolipidaemic individuals, Schaafsma et al. [113] reported a significant decrease in total and LDL-C in men after three weeks of daily supplementation with a fermented milk product $(375 \mathrm{ml})$ containing L. acidophilus and $2.5 \%$ FOS compared with a control milk fermented by traditional yoghurt starters $(375 \mathrm{ml})$. Levels of HDL-C and TAG were unchanged, leading to an improvement in the LDL-C:HDL-C ratio. Kießling and colleagues [114] showed the consumption of a fermented milk product (containing L. acidophilus 145 and B. longum 913) with the addition of $1 \%$ OFS for six weeks to significantly increase total cholesterol in hypercholesterolaemic (but not normocholesterolaemic women), with a lack of effect on either LDL-C or TAG. HDL concentration and the LDL-C to HDL$\mathrm{C}$ ratio were significantly improved in both groups of women, a finding thought to be attributed to the relatively high intake of milk fat (10.5 g/day) as a result of the consumption of $300 \mathrm{~g}$ yoghurt per day. This may explain the lack of effect of a capsule containing a similar probiotic strain on HDL-C by Greany et al. [115] in young healthy men and women. In line with the findings of Schaafsma et al. [113], a reduction in both total and LDL-C was also observed by Ooi et al. after 12 weeks of ingestion of $L$. gasseri and $0.8 \mathrm{~g}$ inulin in hypercholesterolaemic men and women [116, 117]. Interestingly, comparable reductions in total and
LDL-C were observed in these studies even though Ooi and co-workers supplemented with $8.2 \mathrm{~g}$ less of fructan per day. The inclusion of hyperlipidaemic participants, a longer intervention period (three vs. $12 \mathrm{wks}$ ) and/or a different Lactobacillus strain may have contributed to the similar findings in these two studies.

In type II diabetic women, $26 \%$ and $37 \%$ reductions in total cholesterol and TAG levels and a $35 \%$ increase in HDL-C were observed after supplementation for four weeks with a synbiotic shake containing L.acidophilus and B. bifidum and $2 \mathrm{~g}$ of inulin [118]. This is the only study to date which has reported a reduction in fasting TAG levels with a synbiotic product. The lower dose of inulin, relative to those presented in Table 2, suggests a potential synergistic effect of the probiotic strain and inulin on the fasting lipid profile. However, the non-significant $17 \%$ reduction in TAG in the placebo group suggests that other components in the shake (such as oatmeal and textured soy protein), in addition to the raised TAG concentrations ( $>1.7 \mathrm{mmol} / \mathrm{l})$ at baseline, may have contributed to the degree of change in fasting lipid levels in these women.

The majority of research conducted so far with synbiotics has looked at their effect on the composition of the gut microbiota. In one study in healthy subjects, a Bifidobacterium sp. (undefined, strain not defined) fermented milk product with or without $18 \mathrm{~g}$ of inulin was given daily for 12 days [119]. The authors concluded that that the administration of the fermented milk product (probiotic) substantially increased the proportion of bifidobacteria in the gut, but that this increase was not enhanced by the addition of $18 \mathrm{~g}$ of inulin. The composition of the gut microbiota was then assessed two weeks after completing the supplementation period and it was found that subjects who received the fermented milk product and inulin maintained their bifidobacterial population in the gut compared with the subjects receiving the fermented milk product only. Although a synergistic effect on bifidobacteria in the gut was not observed with the synbiotic, these results suggest that either there was better implantation of the probiotic or a prebiotic effect on indigenous bifidobacteria [57]. In a study in elderly subjects, supplementation with a capsule containing $B$. bifidum (BB-02) and B. lactis (BL-01) together with an inulinbased prebiotic was shown to significantly increase total numbers of faecal bifidobacteria including $B$. lactis and B. bifidum, with at least one of these bifidobacteria species still detectable in the faecal samples three weeks after completion of the study [120]. The 
K.G. Jackson and J.A. Lovegrove / Functional foods and lipid metabolism

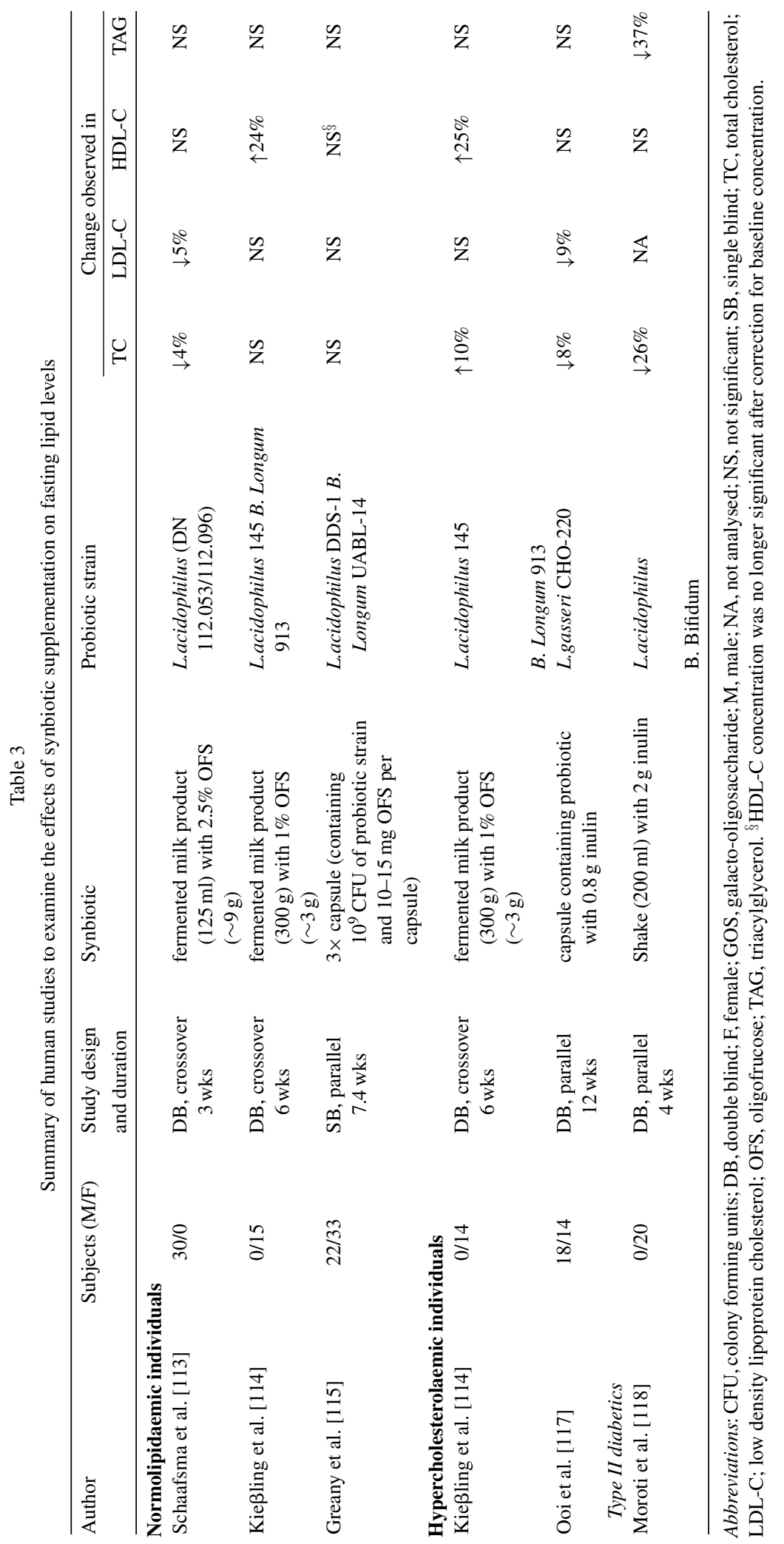


authors commented that the changes in the numbers of B.bifidum were particularly evident in individuals with little or no B. bifidum in their faecal samples at the beginning of the study, suggesting additional benefit of synbiotic consumption in individuals with more unbalanced gut microbiota. Using ${ }^{1} \mathrm{H}$ Nuclear Magnetic Resonance spectroscopy, Ndagijimana et al. reported that feeding healthy individuals with a synbiotic food containing Bifidobacteria longum (strain not defined), Lactobacillus acidophilus (strain not defined) and OFS $(0.5 \mathrm{~g})$ for 30 days significantly influenced the metabolic activity of the intestinal microbiota. In particular, an increase in specific metabolites such as the SCFA butyrate was positively correlated with the number of bifidobacteria in the faeces after supplementation and negatively correlated with the initial level [121]. Maintenance of high numbers of bifidobacteria in the gut may be beneficial in terms of healthy gut function; however, the effect of this synbiotic product on the fasting lipid profile needs to be further investigated. A lower dose of prebiotic $(2.75 \mathrm{~g})$ added to a lactobacillus fermented milk has been shown to significantly increase the number of bifidobacteria when fed over a seven week period in healthy human subjects [112]. If this effect was a result of the synbiotic used in this study, the use of lower doses of prebiotics that can be used in synbiotic preparations should help to reduce gastrointestinal complaints observed when a prebiotic is used alone and improve the acceptability of these types of products by the general public.

\section{Conclusion}

The demographic shift towards an older population in Western societies will result in a higher incidence of CHD, and a significant increase in healthcare costs [122]. As a result, there is considerable interest in dietary strategies which can reduce circulating lipid levels, but which also have comparable efficacy to commonly prescribed drug treatments. Data from animal and in vitro studies have suggested that supplementation with probiotics, prebiotics or synbiotics may be a potential strategy. Our review reports evidence that probiotics significantly reduce plasma total and LDL-C cholesterol particularly in hypercholesterolaemic groups. However, there are differential effects of bacterial species which needs further investigation in randomly controlled studies. Other lipid effects are minimal. Although prebiotics have shown marked effects on both TAG and total cholesterol levels in animal studies, a meta-analysis has reported prebiotics to have a favourable effect on fasting TAG, especially in those with hyperlipidaemia and type II diabetes. However, there are inconsistent findings in relation to prebiotics and further studies are warranted to provide convincing evidence on their lipid lowering properties. Only a limited number of studies have been performed with synbiotics, but initial findings with respect to changes in lipid levels are encouraging, and suggest that in combination with lactic acid bacteria, lower doses of prebiotic fibres could be used in these preparations. This may help to improve the consumer acceptability of these products by reducing the gastrointestinal complaints often associated with some high-dose prebiotic preparations.

A number of mechanisms have been proposed to explain the lipid lowering effects of both probiotics and prebiotics. Probiotics are thought to impact on cholesterol levels via production of SCFA, cholesterol assimilation or increased bile acid secretion. Fermentation of the prebiotic fibres by the gut microflora also increases the levels of SCFA, which are thought to have systemic effects on de novo lipogenesis. Therefore, inconsistent effects on fasting lipid levels observed with prebiotics compared with probiotics may reflect greater dependence on this pathway for modulating lipid metabolism, since de novo lipogenesis is extremely low in humans. Therefore, greater understanding of the mechanisms underlying the impact of probiotics, prebiotics and synbiotics on lipid metabolism, and in comparison with other conventional lipid lowering therapies in populations with raised lipid levels will inform dietary advice for populations 'at risk' of developing CHD.

\section{References}

[1] Martin MJ, Browner WS, Wentworth D, Hulley SB, Kuller LH. Serum-cholesterol, blood-pressure, and mortality Implications from a cohort of 361662 men. Lancet. 1986;2(8513):933-6.

[2] Lewington S, Whitlock G, Clarke R, Sherliker P, Emberson $\mathrm{J}$, Halsey J, et al. Blood cholesterol and vascular mortality by age, sex, and blood pressure: A meta-analysis of individual data from 61 prospective studies with 55000 vascular deaths. Lancet. 2007;370(9602):1829-39.

[3] Third Report of the National Cholesterol Education Program (NCEP) Expert Panel on Detection, Evaluation, and Treatment of High Blood Cholesterol in Adults (Adult Treatment Panel III) final report. Circulation. 2002;106(25):3143-421. 
[4] Assmann G, Cullen P, Schulte H. The Munster Heart Study (PROCAM) - Results of follow-up at 8 years. Eur Heart J. 1998;19:A2-A11.

[5] Austin MA. Plasma triglyceride and coronary heart-disease. Arterioscler Thromb. 1991;11(1):2-14.

[6] Bansal S, Buring JE, Rifai N, Mora S, Sacks FM, Ridker PM. Fasting compared with nonfasting triglycerides and risk of cardiovascular events in women. JAMA. 2007;298(3): 309-16.

[7] Nordestgaard BG, Benn M, Schnohr P, Tybjaerg-Hansen A. Nonfasting triglycerides and risk of myocardial infarction, ischemic heart disease, and death in men and women. JAMA. 2007;298(3):299-308.

[8] Lindman AS, Veierod MB, Tverdal A, Pedersen JI, Selmer R. Nonfasting triglycerides and risk of cardiovascular death in men and women from the Norwegian Counties Study. Eur J Epidemiol. 2010;25(11):789-98.

[9] Jackson KG, Poppitt SD, Minihane AM. Postprandial lipemia and cardiovascular disease risk: Interrelationships between dietary, physiological and genetic determinants. Atherosclerosis. 2012;220(1):22-33

[10] Griffin BA, Zampelas A. Influence of dietary fatty acids on the atherogenic lipoprotein phenotype. Nutr Res Rev. 1995;8(0):1-26.

[11] Chapman MJ, Ginsberg HN, Amarenco P, Andreotti F, Boren J, Catapano AL, et al. Triglyceride-rich lipoproteins and highdensity lipoprotein cholesterol in patients at high risk of cardiovascular disease: Evidence and guidance for management. Eur Heart J. 2010;32(11):1345-61.

[12] Kodama S, Saito K, Tanaka S, Maki M, Yachi Y, Sato M, et al. Influence of fat and carbohydrate proportions on the metabolic profile in patients with Type 2 diabetes: A metaanalysis. Diabetes Care. 2009;32(5):959-65.

[13] Jirillo E, Jirillo F, Magrone T. Healthy effects exerted by prebiotics, probiotics, and symbiotics with special reference to their impact on the immune system. Int J Vitam Nutr Res. 2012;82(3):200-8.

[14] Molinaro F, Paschetta E, Cassader M, Gambino R, Musso G. Probiotics, prebiotics, energy balance, and obesity mechanistic insights and therapeutic implications. Gastroenterol Clin North Am. 2012;41(4):843-54.

[15] Consultation RotJFWE. Health and Nutritional Properties of Probiotics in Food including Powder Milk with live lactic Acid Bacteria; 2001 Contract No.: Document Number.

[16] Mann GV, Spoerry A. Studies of a surfactant and cholesteremia in Maasai. Am J Clin Nutr. 1974;27(5): 464-9.

[17] Mann GV. Factor in yogurt which lowers cholesteremia in man. Atherosclerosis. 1977;26(3):335-40.

[18] Howard AN, Marks J. Effect of milk products on serumcholesterol. Lancet. 1979;2(8149):957.

[19] Bazzare T, Wu S-M, Yuhas J. Total and HDL-cholesterol concentrations following yogurt and calcium supplementation. Nutrition Reports International. 1983;28:1225-32.

[20] Hepner G, Fried R, St Jeor S, Fusetti L, Morin R. Hypocholesterolemic effect of yogurt and milk. Am J Clin Nutr. 1979;32(1):19-24.

[21] Sessions V, Lovegrove J, Dean T, Williams C, Sanders T, Macdonald I, et al. The effects of fermented milk product on plasma cholesterol and apolipoprotein B concentrations in middle aged men and women. Proc Nutr Soc. 1997;56.

[22] Thompson LU, Jenkins DJ, Amer MA, Reichert R, Jenkins A, Kamulsky J. The effect of fermented and unfermented milks on serum cholesterol. Am J Clin Nutr. 1982;36(6):1106-11.

[23] Massey LK. Effect of changing milk and yogurt consumption on human nutrient intake and serum lipoproteins. J Dairy Sci. 1984;67(2):255-62.

[24] McNamara DJ, Lowell AE, Sabb JE. Effect of yogurt intake on plasma lipid and lipoprotein levels in normolipidemic males. Atherosclerosis. [Research Support, Non-U.S. Gov't]. 1989;79(2-3):167-71.

[25] St-Onge MP, Farnworth ER, Savard T, Chabot D, Mafu A, Jones PJ. Kefir consumption does not alter plasma lipid levels or cholesterol fractional synthesis rates relative to milk in hyperlipidemic men: A randomized controlled trial [ISRCTN10820810]. BMC Complement Altern Med. 2002;2:1.

[26] Jaspers D, Massey L, Luedecke L. Effect of consuming yogurts prepared with thress culture strains on human serum lipoproteins. J Food Sci. 1984;49:1178-81.

[27] Ataie-Jafari A, Larijani B, Alavi Majd H, Tahbaz F. Cholesterol-lowering effect of probiotic yogurt in comparison with ordinary yogurt in mildly to moderately hypercholesterolemic subjects. Ann Nutr Metab. 2009;54(1):22-7.

[28] Ejtahed HS, Mohtadi-Nia J, Homayouni-Rad A, Niafar M, Asghari-Jafarabadi M, Mofid V, et al. Effect of probiotic yogurt containing Lactobacillus acidophilus and Bifidobacterium lactis on lipid profile in individuals with type 2 diabetes mellitus. J Dairy Sci. 2011;94(7):3288-94.

[29] Xiao JZ, Kondo S, Takahashi N, Miyaji K, Oshida K, Hiramatsu A, et al. Effects of milk products fermented by Bifidobacterium longum on blood lipids in rats and healthy adult male volunteers. J Dairy Sci. 2003 Jul;86(7):2452-61.

[30] Gobel RJ, Larsen N, Jakobsen M, Molgaard C, Michaelsen KF. Probiotics to obese adolescents; RCT examining the effects on inflammation and metabolic syndrome. J Pediatr Gastroenterol Nutr. 2012.

[31] de Roos NM, Schouten G, Katan MB. Yoghurt enriched with Lactobacillus acidophilus does not lower blood lipids in healthy men and women with normal to borderline high serum cholesterol levels. Eur J Clin Nutr. 1999;53(4):277-80.

[32] Sadrzadeh-Yeganeh H, Elmadfa I, Djazayery A, Jalali M, Heshmat R, Chamary M. The effects of probiotic and conventional yoghurt on lipid profile in women. $\mathrm{Br} \mathrm{J}$ Nutr. 2010;103(12):1778-83.

[33] Anderson JW, Gilliland SE. Effect of fermented milk (yogurt) containing Lactobacillus acidophilus L1 on serum cholesterol in hypercholesterolemic humans. J Am Coll Nutr. 1999;18(1):43-50.

[34] Larkin TA, Astheimer LB, Price WE. Dietary combination of soy with a probiotic or prebiotic food significantly reduces total and LDL cholesterol in mildly hypercholesterolaemic subjects. Eur J Clin Nutr. 2009;63(2):238-45.

[35] Bertolami MC, Faludi AA, Batlouni M. Evaluation of the effects of a new fermented milk product (Gaio) on primary hypercholesterolemia. Eur J Clin Nutr. 1999;53(2):97-101.

[36] Fuentes MC, Lajo T, Carrion JM, Cune J. Cholesterollowering efficacy of Lactobacillus plantarum CECT 7527, 
7528 and 7529 in hypercholesterolaemic adults. Br J Nutr. 2012;1-7.

[37] Jones ML, Martoni CJ, Parent M, Prakash S. Cholesterollowering efficacy of a microencapsulated bile salt hydrolaseactive Lactobacillus reuteri NCIMB 30242 yoghurt formulation in hypercholesterolaemic adults. $\mathrm{Br} \mathrm{J}$ Nutr. 2012;107(10):1505-13.

[38] Jones ML, Martoni CJ, Prakash S. Cholesterol lowering and inhibition of sterol absorption by Lactobacillus reuteri NCIMB 30242: A randomized controlled trial. Eur J Clin Nutr. 2012;66(11):1234-41.

[39] Agerbaek M, Gerdes LU, Richelsen B. Hypocholesterolaemic effect of a new fermented milk product in healthy middle-aged men. Eur J Clin Nutr. 1995;49(5):346-52.

[40] Richelsen B, Kristensen K, Pedersen SB. Long-term (6 months) effect of a new fermented milk product on the level of plasma lipoproteins-a placebo-controlled and double blind study. Eur J Clin Nutr. 1996;50(12):811-5.

[41] Rossouw JE, Burger EM, Van der Vyver P, Ferreira JJ. The effect of skim milk, yoghurt, and full cream milk on human serum lipids. Am J Clin Nutr. 1981;34(3):351-6.

[42] Agerholm-Larsen L, Raben A, Haulrik N, Hansen AS, Manders M, Astrup A. Effect of 8 week intake of probiotic milk products on risk factors for cardiovascular diseases. Eur J Clin Nutr. 2000;54(4):288-97.

[43] Rossi EA, Vendramini RC, Carlos IZ, de Oliveira MG, de Valdez GF. Effect of a new fermented soy milk product on serum lipid levels in normocholesterolemic adult men. Arch Latinoam Nutr. [Clinical Trial Randomized Controlled Trial]. 2003;53(1):47-51.

[44] Karlsson C, Ahrne S, Molin G, Berggren A, Palmquist I, Fredrikson GN, et al. Probiotic therapy to men with incipient arteriosclerosis initiates increased bacterial diversity in colon: A randomized controlled trial. Atherosclerosis. 2010;208(1):228-33.

[45] Steinberg FM, Guthrie NL, Villablanca AC, Kumar K, Murray MJ. Soy protein with isoflavones has favorable effects on endothelial function that are independent of lipid and antioxidant effects in healthy postmenopausal women. Am J Clin Nutr. 2003;78(1):123-30.

[46] Hall WL, Vafeiadou K, Hallund J, Bugel S, Reimann M, Koebnick C, et al. Soy-isoflavone-enriched foods and markers of lipid and glucose metabolism in postmenopausal women: Interactions with genotype and equol production. Am J Clin Nutr. 2006;83(3):592-600.

[47] Potter SM. Soy protein and cardiovascular disease: The impact of bioactive components in soy. Nutr Rev. 1998;56(8):231-5.

[48] Simons LA, Amansec SG, Conway P. Effect of Lactobacillus fermentum on serum lipids in subjects with elevated serum cholesterol. Nutr Metab Cardiovasc Dis. 2006;16(8):531-5.

[49] Naruszewicz M, Johansson ML, Zapolska-Downar D, Bukowska H. Effect of Lactobacillus plantarum 299v on cardiovascular disease risk factors in smokers. Am J Clin Nutr. 2002;76(6):1249-55.

[50] Chang BJ, Park SU, Jang YS, Ko SH, Joo NM, Kim SI, et al. Effect of functional yogurt NY-YP901 in improving the trait of metabolic syndrome. Eur J Clin Nutr. 2011;65(11): 1250-5.
[51] Trautvetter U, Ditscheid B, Kiehntopf M, Jahreis G. A combination of calcium phosphate and probiotics beneficially influences intestinal lactobacilli and cholesterol metabolism in humans. Clin Nutr. 2012;31(2):230-7.

[52] Klein A, Friedrich U, Vogelsang H, Jahreis G. Lactobacillus acidophilus 74-2 and Bifidobacterium animalis subsp lactis DGCC 420 modulate unspecific cellular immune response in healthy adults. Eur J Clin Nutr. 2008;62(5): 584-93.

[53] Guo Z, Liu XM, Zhang QX, Shen Z, Tian FW, Zhang H, et al. Influence of consumption of probiotics on the plasma lipid profile: A meta-analysis of randomised controlled trials. Nutr Metab Cardiovasc Dis. 2011;21(11):844-50.

[54] In'tVeld JH, Shortt C. Selection criteria for probiotic microorganims In: Leeds A, Rowland I, editors. Gut flora and Health - Past, present and future. New York: Royal Society of Medicine Press; 1996. p. 27-36.

[55] Ooi LG, Liong MT. Cholesterol-lowering effects of probiotics and prebiotics: A review of in vivo and in vitro findings. Int J Mol Sci. 2010;11(6):2499-522.

[56] Hylemond P. Metabolism of bile acids in intestinal microflora. In: Danielson H, Sjovall J, editors. Sterols and bile acids. New York: Elsevier Science Publishing; 1985. p. 331-43.

[57] Grill JP, Manginot-Durr C, Schneider F, Ballongue J. Bifidobacteria and probiotic effects: Action of Bifidobacterium species on conjugated bile salts. Curr Microbiol. 1995;31(1):23-7.

[58] Gilliland SE, Nelson CR, Maxwell C. Assimilation of cholesterol by Lactobacillus acidophilus. Appl Environ Microbiol. [Comparative Study]. 1985;49(2):377-81.

[59] Pereira DI, McCartney AL, Gibson GR. An in vitro study of the probiotic potential of a bile-salt-hydrolyzing Lactobacillus fermentum strain, and determination of its cholesterol-lowering properties. Appl Environ Microbiol. 2003;69(8):4743-52.

[60] De Smet I, De Boever P, Verstraete W. Cholesterol lowering in pigs through enhanced bacterial bile salt hydrolase activity. Br J Nutr. 1998;79(2):185-94.

[61] Marteau P, Gerhardt M, Myara A, Bouvier E, Trivin F, Rambaud J. Metabolism of bile sats by alimentary bacteria during transit in human small intestine. Microbiological Ecology in Health \& Disease. 1995;8:151-7.

[62] Liong MT, Shah NP. Acid and bile tolerance and cholesterol removal ability of lactobacilli strains. J Dairy Sci. 2005;88(1):55-66.

[63] Rasic J, Vujicic I, Skrinjar M, Vulic M. Assimilation of cholesterol by some cultures of lactic acid bacteria and bifidobacteria. Biotech Letters. 1992;14:39-44.

[64] Pereira DI, Gibson GR. Cholesterol assimilation by lactic acid bacteria and bifidobacteria isolated from the human gut. Appl Environ Microbiol. 2002;68(9):4689-93.

[65] Klaver FA, van der Meer R. The assumed assimilation of cholesterol by Lactobacilli and Bifidobacterium bifidum is due to their bile salt-deconjugating activity. Appl Environ Microbiol. 1993;59(4):1120-4.

[66] Tahri K, Crociani J, Ballongue J, Schneider F. Effects of three strains of bifidobacteria on cholesterol. Lett Appl Microbiol. 1995;21(3):149-51. 
[67] Hosono A, Tono-oka T. Binding of cholesterol with lactic acid bacteria cells. milchwissenschaft. 1995;50:556-60.

[68] Lin M, Chen T. Reduction of cholesterol by Lactobacillus acidophilus in culture broth. Journal of Drug Analysis. 2000;8:97-102.

[69] Brownawell AM, Caers W, Gibson GR, Kendall CWC, Lewis $\mathrm{KD}$, Ringel Y, et al. Prebiotics and the Health Benefits of Fiber: Current Regulatory Status, Future Research, and Goals. J Nutr. 2012;142(5):962-74.

[70] Dysseler P, Hoffem D. Inulin, an alternative dietary fiber - Properties and quantitative analysis. Eur J Clin Nutr. 1995;49:S145-S52.

[71] Coussement PAA. Inulin and oligofructose: Safe intakes and legal status. J Nutr. 1999;129(7):1412S-7S.

[72] Alles MS, de Roos NM, Bakx JC, van de Lisdonk E, Zock PL, Hautvast J. Consumption of fructooligosaccharides does not favorably affect blood glucose and serum lipid concentrations in patients with type 2 diabetes. Am J Clin Nutr. 1999;69(1):64-9.

[73] Jackson KG, Taylor GRJ, Clohessy AM, Williams CM. The effect of the daily intake of inulin on fasting lipid, insulin and glucose concentrations in middle-aged men and women. $\mathrm{Br}$ J Nutr. 1999;82(1):23-30.

[74] Pedersen A, Sandstrom B, VanAmelsvoort JMM. The effect of ingestion of inulin on blood lipids and gastrointestinal symptoms in healthy females. Br J Nutr. 1997;78(2): 215-22.

[75] Brighenti F, Casiraghi MC, Canzi E, Ferrari A. Effect of consumption of a ready-to-eat breakfast cereal containing inulin on the intestinal milieu and blood lipids in healthy male volunteers. Eur J Clin Nutr. 1999;53(9):726-33.

[76] Kruse HP, Kleessen B, Blaut M. Effects of inulin on faecal bifidobacteria in human subjects. Br J Nutr. 1999;82(5):37582.

[77] van Dokkum W, Wezendonk B, Srikumar TS, van den Heuvel E. Effect of nondigestible oligosaccharides on large-bowel functions, blood lipid concentrations and glucose absorption in young healthy male subjects. Eur J Clin Nutr. 1999;53(1): 1-7.

[78] Luo J, Rizkalla SW, Alamowitch C, Boussairi A, Blayo A, Barry JL, et al. Chronic consumption of short-chain fructooligosaccharides by healthy subjects decreased basal hepatic glucose production but had no effect on insulinstimulated glucose metabolism. Am J Clin Nutr. 1996;63(6): 939-45.

[79] Letexier D, Diraison F, Beylot M. Addition of inulin to a moderately high-carbohydrate diet reduces hepatic lipogenesis and plasma triacylglycerol concentrations in humans. Am J Clin Nutr. 2003;77(3):559-64.

[80] Forcheron F, Beylot M. Long-term administration of inulintype fructans has no significant lipid-lowering effect in normolipidemic humans. Metabolism. 2007;56(8):1093-8.

[81] Russo F, Chimienti G, Riezzo G, Pepe G, Petrosillo G, Chiloiro M, et al. Inulin-enriched pasta affects lipid profile and $\mathrm{Lp}$ (a) concentrations in Italian young healthy male volunteers. Eur J Nutr. 2008;47(8):453-9.

[82] Vulevic J, Drakoularakou A, Yaqoob P, Tzortzis G, Gibson GR. Modulation of the fecal microflora profile and immune function by a novel trans-galactooligosaccharide mixture
(B-GOS) in healthy elderly volunteers. Am J Clin Nutr. 2008;88(5):1438-46.

[83] de Luis DA, de la Fuente B, Izaola O, Conde R, Gutierrez S, Morillo M, et al. Randomised clinical trial with a inulin enriched cookie on risk cardiovascular factor in obese patients. Nutr Hosp. 2010;25(1):53-9.

[84] Giacco R, Clemente G, Luongo D, Lasorella G, Fiume I, Brouns F, et al. Effects of short-chain fructo-oligosaccharides on glucose and lipid metabolism in mild hypercholesterolaemic individuals. Clin Nutr. 2004;23(3):331-40.

[85] Genta S, Cabrera W, Habib N, Pons J, Manrique Carillo I, Grau A, et al. Yacon syrup: Beneficial effects on obesity and insulin resistance in humans. Clin Nutr. 2009;28(2):182-7.

[86] Yen C-H, Kuo Y-W, Tseng Y-H, Lee M-C, Chen H-L. Beneficial effects of fructo-oligosaccharides supplementation on fecal bifidobacteria and index of peroxidation status in constipated nursing-home residents-A placebo-controlled, diet-controlled trial. Nutr. 2011;27(3):323-8.

[87] Hidaka H, Hirayama M, Tokunaga T, Eida T. The effects of undigestible fructooligosaccharides on intestinal microflora and various physiological functions on human health. Furda IBC, editor.; 1990.

[88] Davidson MH, Maki KC, Synecki C, Torri SA, Drennan KB. Effects of dietary inulin on serum lipids in men and women with hypercholesterolemia. Nutr Res. 1998;18(3):503-17.

[89] Causey JL, Galiaher DD, Slavin JL. Effect of inulin consumption on lipid and glucose metabolism in healthy men with moderately elevated cholesterol. FASEB J. 1998;20;12(5):A817-A.

[90] Balcazar-Munoz BR, Martinez-Abundis E, Gonzalez-Ortiz M. Effect of oral inulin administration on lipid profile and insulin sensitivity in dyslipidemic obese subjects. Rev Med Chil. 2003;131(6):597-604.

[91] Yamashita K, Kawai K, Itakura M. Effects of fructooligosaccharides on blood-glucose and serum-lipids in diabetic subjects. Nutr Res. 1984;4(6):961-6.

[92] Luo J, Van Yperselle M, Rizkalla SW, Rossi F, Bornet FRJ, Slama G. Chronic consumption of short-chain fructooligosaccharides does not affect basal hepatic glucose production or insulin resistance in type 2 diabetics. J Nutr. 2000;130(6):1572-7.

[93] Brighenti F. Dietary Fructans and serum triacylglycerols: A meta-analysis of randomized controlled trials. J Nutr. 2007;137(11):2552S-6S.

[94] Kok NN, Morgan LM, Williams CM, Roberfroid MB, Thissen JP, Delzenne NM. Insulin, glucagon-like peptide 1, glucose-dependent insulinotropic polypeptide and insulinlike growth factor I as putative mediators of the hypolipidemic effect of oligofructose in rats. J Nutr. 1998;128(7): 1099-103.

[95] Roberfroid M. Dietary fiber, inulin and oligofructose: A review comparing their physiological effects. Crit Rev Food Sci Nutr. 1993;33:102-48.

[96] Beards E, Tuohy K, Gibson G. A human volunteer study to assess the impact of confectionery sweeteners on the gut microbiota composition. Br J Nutr. 2010;104(5):701-8.

[97] Bodinham CL, Frost GS, Robertson MD. Acute ingestion of resistant starch reduces food intake in healthy adults. Br J Nutr. 2010;103(6):917-22. 
[98] Tuohy KM, Conterno L, Gasperotti M, Viola R. Upregulating the Human Intestinal Microbiome Using Whole Plant Foods, Polyphenols, and/or Fiber. J Agric Food Chem. 2012;60(36):8776-82.

[99] Delzenne NM, Kok N, Fiordaliso MF, Deboyser DM, Goethals FM, Roberfroid MB. Dietary fructooligosaccharides modify lipid-metabolism in rats. Am J Clin Nutr. 1993;57(5):S820-S

[100] Gibson GR, McCartney AL. Modification of the gut flora by dietary means. Biochem Soc Trans. 1998;26(2):222-8.

[101] Wolever TMS, Brighenti F, Royall D, Jenkins AL, Jenkins DJA. Effect of rectal infusion of short chain fatty-acids in human-subjects. Am J Gastroenterol. 1989;84(9):1027-33.

[102] Demigne C, Morand C, Levrat MA, Besson C, Moundras C, Remesy C. Effect of propionate on fatty-acid and cholesterol-synthesis and on acetate metabolism in isolated rat hepatocytes. Br J Nutr. 1995;74(2):209-19.

[103] Van Loo J, Cummings JH, Delzenne N, Englyst H, Franck A, Hopkins M, et al. Functional food properties of non-digestible oligosaccharides: A consensus report from the ENDO project (DGXII AIRII-CT94-1095). Br J Nutr. 1999;81(2): 121-32.

[104] Kabel MA, Kortenoeven L, Schols HA, Voragen AGJ. In vitro fermentability of differently substituted xylooligosaccharides. J Agric Food Chem. 2002;50(21):6205-10.

[105] Walton GE, van den Heuvel EGHM, Kosters MHW, Rastall RA, Tuohy KM, Gibson GR. A randomised crossover study investigating the effects of galacto-oligosaccharides on the faecal microbiota in men and women over 50 years of age. Br J Nutr. 2012;107(10):1466-75.

[106] Wolever TMS, Spadafora PJ, Cunnane SC, Pencharz PB. Propionate inhibits incorporation of colonic [1,2-C13]acetate into plasma-lipids in humans. Am J Clin Nutr. 1995;61(6): 1241-7.

[107] Fiordaliso M, Kok N, Desager JP, Goethals F, Deboyser D, Roberfroid M, et al. Dietary oligofructose lowers triglycerides, phospholipids and cholesterol in serum and very-lowdensity lipoproteins of rats. Lipids. 1995;30(2):163-7.

[108] Delzenne NM, Kok N. Effect of non-digestible fermentable carbohydrates on hepatic fatty acid metabolism. Biochem Soc Trans. 1998;26(2):228-30

[109] Arora T, Loo RL, Anastasovska J, Gibson GR, Tuohy KM, Sharma RK, et al. Differential effects of two fermentable carbohydrates on central appetite regulation and body composition. Plos One. 2012;7(8).

[110] Knapper JME, Puddicombe SM, Morgan LM, Fletcher $\mathrm{JM}$. Investigations into the actions of glucose-dependent insulinotrophic polypeptide and glucagon-like peptide-1(736)amide on lipoprotein-lipase activity in explants of rat-adipose tissue. J Nutr. 1995;125(2):183-8.
[111] Delzenne NM. The hypolipidaemic effect of inulin: When animal studies help to approach the human problem Invited commentary. Br J Nutr. 1999;82(1):3-4.

[112] Roberfroid MB. Prebiotics and synbiotics: Concepts and nutritional properties. Br J Nutr. 1998;80(4):S197-S202.

[113] Schaafsma G, Meuling WJA, van Dokkum W, Bouley C. Effects of a milk product, fermented by Lactobacillus acidophilus and with fructo-oligosaccharides added, on blood lipids in male volunteers. Eur J Clin Nutr. 1998;52(6):436-40.

[114] Kiessling G, Schneider J, Jahreis G. Long-term consumption of fermented dairy products over 6 months increases HDL cholesterol. Eur J Clin Nutr. 2002;56(9):843-9.

[115] Greany KA, Bonorden MJL, Hamilton-Reeves JM, McMullen MH, Wangen KE, Phipps WR, et al. Probiotic capsules do not lower plasma lipids in young women and men. Eur J Clin Nutr. 2008;62(2):232-7.

[116] Ooi LG, Ahmad R, Yuen KH, Liong MT. Lactobacillus acidophilus $\mathrm{CHO}-220$ and inulin reduced plasma total cholesterol and low-density lipoprotein cholesterol via alteration of lipid transporters. J Dairy Sci. 2010;93(11):5048-58.

[117] Ooi LG, Ahmad R, Yuen KH, Liong MT. Lactobacillus acidophilus CHO-220 and inulin reduced plasma total cholesterol and low-density lipoprotein cholesterol via alteration of lipid transporters (vol 93, pg 5048, 2010). J Dairy Sci. 2011;94(5):2658.

[118] Moroti C, Souza Magri LF, Rezende Costa Md, Cavallini DCU, Sivieri K. Effect of the consumption of a new symbiotic shake on glycemia and cholesterol levels in elderly people with type 2 diabetes mellitus. Lipids Health Dis. 2012;11:2936.

[119] Bouhnik Y, Flourie B, Andrieux C, Bisetti N, Briet F, Rambaud JC. Effects of Bifidobacterium sp fermented milk ingested with or without inulin on colonic bifidobacteria and enzymatic activities in healthy humans. Eur J Clin Nutr. 1996;50(4):269-73.

[120] Bartosch S, Woodmansey EJ, Paterson JCM, McMurdo MET, Macfarlane GT. Microbiological effects of consuming a synbiotic containing Bifidobacterium bifidum, Bifidobacterium lactis, and oligofructose in elderly persons, determined by real-time polymerase chain reaction and counting of viable bacteria. Clin Infect Dis. 2005;40(1):28-37.

[121] Ndagijimana M, Laghi L, Vitali B, Placucci G, Brigidi P, Guerzoni ME. Effect of a synbiotic food consumption on human gut metabolic profiles evaluated by H-1 Nuclear Magnetic Resonance spectroscopy. Int J Food Microbiol. 2009;134(1-2):147-53.

[122] Odden MC, Coxson PG, Moran A, Lightwood JM, Goldman $\mathrm{L}$, Bibbins-Domingo $\mathrm{K}$. The impact of the aging population on coronary heart disease in the united states. Am J Med. [Article]. 2011;124(9):827-U1506. 